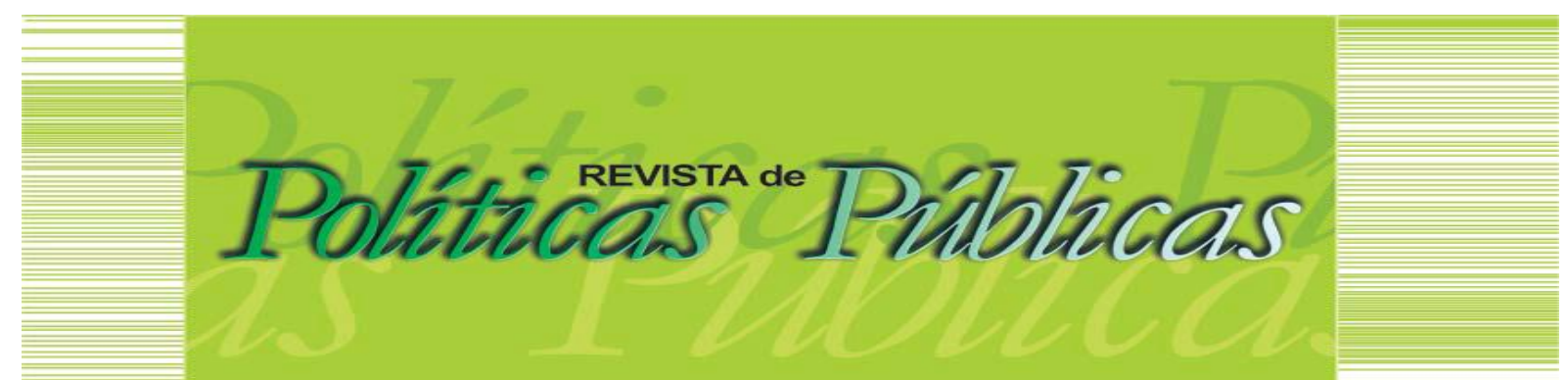

\title{
ACOMPANHAMENTO ESPECIALIZADO DE ADOLESCENTES EM SITUAÇÃO DE VIOLÊNCIA SEXUAL NA CIDADE DE MANAUS
}

\author{
Cristiane Bonfim Fernandez ${ }^{1}$ \\ Susy Ellen Pacheco da Silva ${ }^{2}$
}

\section{Resumo}

Este artigo faz uma reflexão sobre o acompanhamento especializado de adolescentes em situação de violência sexual considerando a perspectiva de adolescentes e familiares atendidos no Centro de Referência Especializada em Assistência Social (CREAS) na cidade de Manaus. Trata de uma pesquisa empírica cujos sujeitos são quatro adolescentes e quatro mães atendidas pelo Serviço de Proteção e Atendimento Especializado a Famílias e Indivíduos (PAEFI). Os resultados apontam que o CREAS, como unidade especializada, tem cumprido seu papel no enfrentamento da violência sexual contra adolescentes, garantindo à população usuária o direito de um atendimento qualificado que tem contribuído para 0 fortalecimento das famílias, a redução e a superação dos impactos da violência sexual na vida de adolescentes e de seus familiares.

Palavras-chave: Adolescentes. Violência sexual. Família.

\section{SPECIALIZED MONITORING OF ADOLESCENTS IN SITUATION OF SEXUAL VIOLENCE IN THE CITY OF MANAUS}

\begin{abstract}
This paper reflects on the specialized monitoring of adolescents in situations of sexual violence considering the perspective of adolescents and family members attended at the Specialized Reference Center for Social Assistance (CREAS) in the city of Manaus. This is an empirical research whose subjects are four adolescents and four mothers attended by the Protection and Specialized Service to Families and Individuals (PAEFI). The results show that CREAS, as a specialized unit, has fulfilled its role in facing sexual violence against adolescents, guaranteeing the user population the right to a qualified service that has contributed to the strengthening of families, reducing and overcoming the impacts of violence in the lives of adolescents and their families.
\end{abstract}

Keywords: Adolescents. Sexual violence. Family

Artigo recebido em: 28/01/2020 Aprovado em: 28/10/2020 DOl: http://dx.doi.org/10.18764/2178-2865.v24n2p511-531.

\footnotetext{
${ }_{1}^{1}$ Assistente Social. Doutora em Política Social pela UnB .Professora do Departamento de Serviço Social da UFAM e do Programa de Pós-Graduação em Serviço Social e Sustentabilidade na Amazônia.E-mail: cristiane@ufam.edu.br 2 Assistente Social. Mestre em Serviço Social e Sustentabilidade na Amazônia pela UFAM. Assistente Social da Aldeias Infantis SOS. E-mail: susy.eps@gmail.com
} 


\section{INTRODUÇÃO}

Em todo o mundo, aproximadamente 120 milhões de meninas com menos de 20 anos foram forçadas a ter relações sexuais ou a praticar outros atos sexuais - é o que apontou o relatório do UNICEF (2014), baseado em 190 países. Essa violência sexual geralmente vem acompanhada de negligência, maus-tratos físicos e emocionais, constituindo-se como uma das mais perturbadoras violações do direito da infância. Ela fere a dignidade da pessoa humana e tem efeitos devastadores na vida da criança e do adolescente, das famílias e de toda a sociedade.

No Brasil, os dados também são alarmantes. Segundo o Sistema de Informação de Agravos de Notificação (SINAN), em 2011, em relação ao total das notificações ocorridas, 88,5\% das vítimas eram do sexo feminino, mais de 50\% eram menores de 13 anos, $46 \%$ não possuíam o ensino fundamental completo, $51 \%$ eram de cor preta ou parda e $12 \%$ haviam sido casados anteriormente. No cômputo geral, mais de $70 \%$ dos estupros vitimizaram crianças e adolescentes (CERQUEIRA; COELHO, 2014).

O Atlas da Violência 2018, produzido pelo Instituto de Pesquisa e Economia Aplicada (IPEA), ressalta que 68\% dos casos de estupro registrados no sistema de saúde em 2016 se referem a crianças e adolescentes, sendo quase um terço dos agressores das crianças (até 13 anos) amigos e conhecidos da vítima e outros 30\% , familiares mais próximos, como pais, mães, padrastos e irmãos. Quando o perpetrador era conhecido da vítima, $54,9 \%$ dos casos se referiam a ações que já vinham acontecendo antes e 78,5\% a ações ocorridas na própria residência (CERQUEIRA et al., 2018).

Esse cenário aponta a extensão dos crimes sexuais que vêm ocorrendo no Brasil e no mundo. E no estado do Amazonas não é diferente. A Secretária de Segurança Pública do Amazonas registrou a ocorrência, em 2018, de 809 denúncias de casos de violência sexual contra crianças e adolescentes, o que representa um aumento de quase 18\% em relação ao ano de 2017, em que for am registrados 686 casos na capital (SSP-AM, 2019).

Os registros de violação de direitos contra crianças e adolescentes no estado são altos. De acordo com dados do Disque 100, o Amazonas, entre janeiro de 2011 e 2019 (Tabela 1), registrou 6.480 denúncias de violência sexual contra crianças e adolescentes, ocupando $02^{\circ}$ lugar no ranking da Região Norte (atrás apenas do Pará) e o $13^{\circ}$ lugar no ranking brasileiro entre os 27 estados da federação com maior número de registros (BRASIL, 2019). 
Tabela 1 - Registro de denúncias de violência sexual contra crianças e adolescentes no Amazonas - Canal Disque 100

\begin{tabular}{|c|c|c|c|c|c|c|c|c|c|c|}
\hline Ano & $\begin{array}{l}\text { Abuso } \\
\text { Sexual }\end{array}$ & Estupro & $\begin{array}{l}\text { Exploração } \\
\text { Sexual }\end{array}$ & $\begin{array}{c}\text { Exploração } \\
\text { Sexual no } \\
\text { Turismo }\end{array}$ & Grooming & Outros & $\begin{array}{l}\text { Pomografia } \\
\text { Infantil }\end{array}$ & Sexting & Total & $\%$ \\
\hline 2011 & 276 & 1 & 90 & & 1 & 4 & 3 & & 375 & $5,8 \%$ \\
\hline 2012 & 974 & & 318 & & 3 & 16 & 10 & 5 & 1326 & $20,4 \%$ \\
\hline 2013 & 736 & & 211 & 4 & 2 & 10 & 8 & 7 & 978 & $15 \%$ \\
\hline 2014 & 610 & & 222 & 2 & 3 & 13 & 8 & 5 & 863 & $13,4 \%$ \\
\hline 2015 & 482 & & 186 & 1 & 4 & 12 & 24 & 4 & 713 & $11 \%$ \\
\hline 2016 & 488 & 1 & 175 & 1 & 9 & 17 & 20 & 15 & 726 & $11,2 \%$ \\
\hline 2017 & 458 & & 160 & 2 & 1 & 3 & 17 & 4 & 645 & $10 \%$ \\
\hline 2018 & 374 & & 117 & 1 & 2 & 1 & 5 & 4 & 504 & $7,7 \%$ \\
\hline 2019 & 283 & & 52 & & 3 & 1 & 9 & 2 & 350 & $5,5 \%$ \\
\hline Total & 4.681 & 2 & 1531 & 11 & 28 & 77 & 104 & 46 & 6.480 & $100 \%$ \\
\hline$\%$ & $72 \%$ & $0,03 \%$ & $24 \%$ & $0,1 \%$ & $0,4 \%$ & $1,3 \%$ & $1,47 \%$ & $0,7 \%$ & $100 \%$ & \\
\hline
\end{tabular}

Consoante as informações do quadro 1, o abuso sexual é o tipo de violência sexual que predomina nos registros de denúncias no Amazonas, totalizando $72 \%$ dos casos, seguido da exploração sexual, com $24 \%$. No entanto, chama-nos a atenção duas formas de violência sexual grooming e sexting - associadas diretamente ao uso da internet e da tecnologia. Grooming é o aliciamento de crianças e adolescentes por meio da internet para obtenção de benefícios sexuais e ocorre quando uma pessoa estabelece um diálogo/uma amizade com menores de idade a fim de convencê-los a se envolverem em atividades sexuais. Sexting (junção das palavras sex e texting) refere-se à divulgação de conteúdos eróticos e sensuais através de celulares, ou seja, por mensagem de textos com conteúdo sexual.

A proteção a crianças e adolescentes em situação de violência sexual, principalmente no Amazonas, tem se mostrado cada dia mais desafiadora, não apenas pela dificuldade de mobilidade, mas também pela cultura, que muitas vezes influencia na naturalização de relações sexuais entre crianças/adolescentes e adultos (LEITÃO, 2016). A forma naturalizada de tratar a prática de violência sexual contra crianças e adolescentes no Amazonas pode ser vista quando é explicada, muitas vezes, pelo "enxerimento" ${ }^{1}$ da vítima, dando a entender que a criança ou adolescente estaria provocando sexualmente 0 agressor, o que torna o enfrentamento dessa problemática um desafio a mais no cotidiano de lutas pela garantia de proteção integral dessa população.

Esse gravíssimo cenário da violência sexual contra crianças e adolescentes em todo 0 mundo, e particularmente no estado do Amazonas, justifica estudos sobre o tema e impulsiona as autoras deste artigo a conhecer a realidade da violência sexual contra adolescentes na cidade de Manaus, assim como seus impactos na vida da vítima, dos familiares e da sociedade. Busca-se, ainda, perceber o modo como os Centros de Referência Especializada de Assistência Social (CREAS) vêm 
oferecendo/garantindo os serviços especializados para crianças e adolescentes em situação de violência sexual e suas famílias.

Assim, a questão central norteadora da pesquisa é: "O que pensam as adolescentes em situação de violência sexual e os familiares a respeito do atendimento recebido no CREAS em Manaus e, particularmente, de que forma as ações desenvolvidas por esse equipamento têm impactado a vida dessas adolescentes e suas famílias?".

Para responder a tal questionamento, foi realizada na cidade de Manaus, entre 2018 e 2019, a pesquisa intitulada "O acompanhamento realizado pelo CREAS a adolescentes em situação de violência sexual em Manaus", aprovada pelo Comitê de Ética da Universidade Federal do Amazonas. 0 lócus da pesquisa foram o CREAS Cidade Nova e o CREAS Leste, localizados nas zonas de maior vulnerabilidade a violações de direitos e desigualdade sociais na cidade de Manaus. Foram entrevistadas 5 profissionais das unidades pesquisadas, 4 mães representando as famílias e 4 adolescentes em situação de violência sexual acompanhados há mais de 6 meses pelo CREAS. No entanto, considerando o objetivo deste artigo, são abordadas somente as falas das adolescentes e de seus familiares como objeto de reflexão.

Este artigo contempla, portanto, uma discussão sobre conceitos de violência e exploração sexual contra criança e adolescente, aborda a resposta do Estado a essa problemática, principalmente por meio do Centro de Referência Especializada de Assistência Social (CREAS) e apresenta a visão de adolescentes e familiares sobre 0 atendimento especializado recebido nesse Centro, por meio do Serviço de Proteção e Atendimento Especializado a Famílias e Indivíduos (PAEFI).

\section{VIOLÊNCIA SEXUAL CONTRA CRIANÇAS E ADOLESCENTES}

A violência contra criança e adolescente é parte intrínseca da história brasileira. 0 não reconhecimento da criança como um "ser em desenvolvimento" é uma das violências fundantes. No século XVIII, a criança era considerada como um adulto incompetente e seu valor só existia quando relacionado ao futuro (ROURE, 1996). Nessa perspectiva, não havia, no Brasil colônia, uma valorização da infância, sendo práticas comuns o assassinato, o extermínio, a tortura e a punição de crianças brancas, negras e índias. No final do século XIX e início do século XX, crianças eram usadas como mão de obra barata nas indústrias existentes. 0 problema maior é pensar que as violências cometidas contra crianças e adolescentes eram consideradas como medidas normais por não serem eles considerados seres humanos, sendo uma dessas manifestações abusivas a violência sexual.

Dessa forma, a violência sexual é a expressão da violência presente na sociedade no passado e no presente e atinge principalmente a infância, estando geralmente associada a castigos 
físicos, à violência psicológica e à negligência, pois se sabe que muito raramente a criança sofre apenas uma forma de violência. Mas em que consiste a violência sexual? Há entendimentos diferenciados conforme os estudiosos e os contextos sociopolítico em que são produzidas as interpretações. Sendo assim, é difícil falar de um único conceito. No entanto, é consenso entre os especialistas sobre violência sexual contra crianças e adolescentes sua configuração como relação autoritária de poder, pois o agressor é um sujeito em situação de mais poder que obriga a outra pessoa a realizar práticas sexuais contra a vontade, seja por meio de força física, seja por influência psicológica, pelo uso de armas ou de drogas. Há, portanto, uma relação de desequilíbrio de pesos/poderes de conhecimento, autoridade, maturidade (FALEIROS, 2000).

Percebe-se, assim, uma relação de dominação em que o agressor impõe seus interesses e desejos sexuais sobre o outro. Além disso, há de se considerar também a assimetria de gênero e de idade, pois tal relação geralmente envolve homens adultos e crianças e adolescentes do sexo feminino. A violência constitui-se, portanto, uma ação em que as pessoas são proibidas de manifestar sua vontade, tornando-se submissas aos desejos alheios e perdendo, assim, a sua autonomia (SOUZA; SILVA, 2002).

Em um sentido mais restrito, violência sexual pode ser compreendida como sinônimo de abuso sexual, vitimização sexual, sevícia sexual, mas pode ter um sentido mais amplo - segundo Vasconcelos e Garcia (2004), a violência sexual contempla o abuso sexual (intra e extrafamiliar) e a exploração sexual, sendo a pornografia e a prostituição infantil, o turismo sexual e 0 tráfico as modalidades mais comuns de exploração sexual comercial.

A pornografia infantil é crime previsto nos artigos 240 e 241 do Estatuto da Criança e Adolescentes (ECA), com pena prevista de 3 a 8 anos de reclusão, constituindo-se delito produzir, vender, divulgar e publicar por qualquer meio de comunicação, incluindo a internet, fotografias e imagens com pornografia ou cenas de sexo explícito envolvendo criança ou adolescentes. Importante ressaltar que, em tempos tecnológicos, a exposição da intimidade sexual é crime, conforme art. 216-B, do Código Penal Brasileiro: "Produzir, fotografar, filmar ou registrar, por qualquer meio, conteúdo com cena de nudez ou ato sexual ou libidinoso de caráter íntimo e privado sem autorização dos participantes".

A prostituição infantil ocorre quando crianças e adolescentes são utilizados sexualmente em troca de remuneração ou de outra retribuição. Do ponto de vista comercial, o sexo jovem é considerado uma mercadoria disponível para compra e venda, ou seja, na indústria do sexo, criança é tratada como objeto sexual. Há a coisificação do outro - criança e adolescente - e a completa violação do seu direito ao respeito, à liberdade e à dignidade sexual. 
Na Convenção 182 da Organização Internacional do Trabalho (OIT), de 1999, a prostituição infantil ou infanto-juvenil é elencada como uma das piores formas de trabalho infantil. Dos Santos, Ippolito e Neumann (2004) conceituam prostituição infantil como trabalho sexual infanto-juvenil autônomo, em que o adolescente de camada popular vende seu corpo em troca de uma remuneração ou para sobrevivência, ou para custear o vício em drogas, fazendo isso sem mediação, sem agenciamento. Descrevem também as trocas sexuais - oferta de sexo para obtenção de favores, como comida e roupas -, que se constituem práticas eventuais e, por isso, compreendidas como trocas sexuais e, não, como trabalho sexual.

Há, ainda, o entendimento da prostituição infantil como trabalho sexual infanto-juvenil agenciado, em que a venda do sexo é intermediada por uma ou mais pessoas - a chamada rede de exploração sexual. Nogueira Neto $(2015$, p. 6) ressalta que "tecnicamente, no Brasil, se usou e se usa a expressão 'prostituição' quando do abuso sexuais de pessoas menores de 18 anos, com fins lucrativos, isto é, como forma de exploração da sexualidade para fins de 'lascívia alheia' (lenocínio, rufianismo)".

É importante destacar que o favorecimento da prostituição ou de outra forma de exploração sexual de criança e adolescente ou de vulnerável, conforme Art. 218b², Lei 12.989/2014, é crime, e mais do que isso, é crime HEDIONDO ${ }^{3}$. Noutras palavras, a legislação brasileira é explícita em definir a exploração sexual de criança e adolescente como algo repugnante, reprovável, imoral, constituindo-se crime que fere a dignidade humana.

Outra forma de exploração sexual de crianças e adolescentes é o turismo para fins sexuais (ou orientado para exploração sexual), também chamado sexo-turismo ou turismo sexual. Como o próprio nome sugere, organiza-se o turismo com fins encobertos para a satisfação de prazer sexual aos turistas, sejam nativos, sejam estrangeiros.

Associado a esse tipo de turismo, encontra-se o tráfico para fins de exploração sexual, que, segundo Dos Santos, Ippolito e Neumann (2004, p. 91), é uma das formas mais perversas de exploração sexual, uma vez que "envolve atividades de cooptação e/ou aliciamento, rapto, intercâmbio, transferência e hospedagem de pessoas recrutadas para essa finalidade". Está relacionado à exploração de crianças e adolescentes por turistas estrangeiros ou do próprio país, o que ocorre geralmente com a cumplicidade de agências de viagens, guias turísticos, bares, lanchonetes e restaurantes. Noutras palavras, há uma rede de exploração sexual sustentando este tipo de crime. Para Siqueira e Quinteiro (2013, p. 108), o tráfico de pessoas significa 
entrega ou aceitação de pagamentos ou benefícios para obter consentimento de uma pessoa que tenha autoridade sobre a outra para fins de exploração.

Segundo Veronese (2005, p. 65), na exploração sexual infanto-uvenil "crianças e adolescentes tornam-se escravos e não têm a quem socorrer para garantir os seus direitos, muito menos de proteção do Estado". Em tais circunstâncias, a infância é forçada a ter relações sexuais com vários clientes, é escravizada, não consegue fugir, não recebe nenhuma vantagem financeira. Está inserida na rede de exploração sexual.

Ante 0 exposto, fica evidente que "A violência sexual contra crianças e adolescentes é uma violação dos direitos da pessoa humana e da pessoa em desenvolvimento; direitos à integridade física e psicológica, ao respeito e a dignidade, ao desenvolvimento físico, psicológico, moral e sexual sadios" (FALEIROS, 2004, p. 76).

No Brasil, esse tipo de violência tem uma vítima preferencial, a menina, a adolescente, a mulher pobre que vive uma miséria econômica aguda, tornando-se, assim, uma espécie de subcidadãs. Esse contingente de vítimas é mais vulnerável ao tráfico de exploração sexual, sendo muitas delas escravas sexuais no estrangeiro. Essa violência, contudo, atinge também crianças do sexo masculino, pois estas, principalmente nos países pobres, são raptadas e vendidas para todo tipo de exploração.

Quando se trata de abuso/violência sexual, doméstica ou intrafamiliar, há várias compreensões. Segundo Azambuja (2011, p. 90), a violência sexual intrafamiliar é "aquela praticada por agressor que faz parte do grupo familiar da vítima, considerando não apenas família consanguínea, como também as famílias adotivas e socioafetivas, onde se incluem os companheiros da mãe e do pai, ou, ainda a pessoa de confiança da criança".

Para Podestá e Rovea (2005, p. 23) o abuso sexual infantil intrafamiliar (o incesto) "referese ao contexto da própria família, sobre a qual pesa uma interdição legal e cultural para sua realização, onde 0 abusador pode ser o pai, irmão, avós, tios, padrastos ou familiares mais chegados à vítima". Fernandez e Ribeiro (2005, p. 53) pontuam que "O incesto ainda é um tabu em muitas famílias. Aceitálo é um abuso de poder em que são rompidas as relações de confiança entre os componentes da família".

Os casos de incesto são gerados geralmente por abusadores homens, e as maiores vítimas, como já mencionado, são as meninas. Portanto, trata-se de um problema vinculado ao gênero. Esta perspectiva deve estar presente quando se discute sobre violência sexual contra crianças e adolescentes. A sociedade com fortes traços machistas produz violência sexual contra crianças e adolescentes principalmente em espaços de dominação masculina. 
O cenário de violência em que se encontra imersa a sociedade aponta para a perda da sensibilidade e da razão humana. A violência sexual infantil, principalmente, aponta a ausência do reconhecimento da criança como pessoa e, consequentemente, para a perda da sua dignidade, inclusive da dignidade sexual. Diante de tal cenário, qual tem sido a resposta do Estado a esse gravíssimo problema social que afeta, como visto, pessoas no mundo inteiro?

\subsection{Marcos jurídicos e políticas públicas}

No século XX houve avanços importantes em relação ao tratamento dado à infância na normativa internacional e nacional, como a Declaração dos Direitos Humanos (1948), a Declaração dos Direitos da Criança de 1959, a Constituição Federal Brasileira de 1988, a aprovação da Convenção das Nações Unidas sobre os Direitos da Criança, em 1989 e o Plano Nacional de Enfrentamento da Violência Sexual InfantoJuvenil (Plano Nacional) em 2000. É nesse cenário de conquistas que as crianças em situação de violência sexual adquirem relevância para a sociedade e para o Estado Brasileiro.

Os marcos normativos nacionais e internacionais referenciais são imprescindíveis para 0 reconhecimento e a garantia dos direitos sexuais e para o enfrentamento da exploração sexual de crianças e adolescentes. Devem ser explicitados obrigatoriamente na construção de reflexão teórica e, também, na operacionalização de práticas sociopolíticas estatais, configurando-se como paradigmas ético-políticos da dignidade e da liberdade sexual (NOGUEIRA NETO, 2015). Isso significa que, em um verdadeiro Estado Democrático de Direitos, a sexualidade infantil é vista com base na perspectiva dos direitos, constituindo-se a violação deste direito um desrespeito à dignidade e à liberdade sexual.

$\mathrm{Na}$ sociedade contemporânea, a criança é considerada sujeito de direito e conta com proteção jurídica internacional - a Convenção das Nações Unidas sobre os Direitos da Criança - que apresenta as obrigações dos Estados com a infância, incluindo proteção contra qualquer forma de exploração e de abuso sexual, e, quando houver violação de direitos, medidas devem ser adotadas para proteger integralmente a criança: "Os estados partes, que aderiram à Convenção, possuem obrigações. [...] este documento tem força de lei internacional e, assim, cada Estado não poderá violar seus preceitos, como também deverá tomar todas as medidas positivas para promovê-los" (FERRAZA; VERONESE, 2005, p. 24).

O Plano Nacional se constitui a referência nacional para a formulação e a implementação de políticas e programas voltadas para crianças e adolescente em situação de violência sexual. Sofreu uma atualização/revisão em 2013, com alterações em seus eixos estratégicos, cuja redação ficou assim constituída: (1) Estudos e Pesquisas - produção de conhecimento como instrumento de 
compreensão e intervenção na realidade; (2) Comunicação e Mobilização - comunicação como fundamento para garantir e consolidar a rede de proteção, articulando e mobilizando comissões, fóruns, entidades; (3) Defesa e responsabilização - os agressores, sejam indivíduos, sejam redes de exploração, devem ser responsabilizados por seus atos; (4) Atenção - atendimento especializado qualificado em rede para crianças e seus familiares; (5) Prevenção - ações preventivas de educação e sensibilização contra a violência sexual; (6) Participação e Protagonismo - promoção da participação de crianças e adolescentes pela defesa de seus direitos (BRASIL, 2013). A articulação desses eixos, que valoriza a infância, garante um olhar multifacetado para o enfrentamento da violência sexual contra crianças e adolescente.

A legislação brasileira tem sofrido alterações ao longo de sua história. O Código Penal de 1940, por meio da Lei 12.015 de 2009, inseriu um novo termo/conceito em seu título VI que trata de crimes contra a dignidade sexual, e um capítulo somente para crimes contra a liberdade sexual em lugar de crimes contra os costumes (BRASIL, 2009a). E o que isso significa? Uma mudança de olhar, de paradigma em relação à forma de olhar a sexualidade. Como afirma Nogueira Neto (2015), trocouse a chave hermenêutica para a interpretação dessas normas penais e para tipificação criminal em concreto de condutas predatórias sexuais.

Se, por um lado, a sexualidade é protegida pela legislação brasileira, por outro, existe uma sociedade do consumo em que os desejos são moldados. 0 aliciador sabe que usando o discurso dos sonhos e dos desejos, ele irá atrair mais facilmente a pessoa, geralmente uma mulher, prometendo-lhe a felicidade. Valores são impostos, principalmente por meios da comunicação, prevalecendo uma das ideologias da sociedade de consumo: o corpo da mulher é objeto desejável e pode ser vendido e comprado.

Do ponto de vista da sociedade capitalista, a exploração e a comercialização do sexo são atividades legítimas, como em uma empresa qualquer. É um mercado de alta lucratividade, florescente em muitos países do mundo e de grande importância nas economias nacionais. De um lado, a indústria do sexo passa a atuar em redes que organizam o tráfico de mulheres (adultas, adolescentes e crianças) para o comércio sexual, estabelecem rotas e formam verdadeiros impérios que equipam prostíbulos, boates, casas de show e indústria pornográfica (FALEIROS, 2004). De outro, há um enfraquecimento do Estado social brasileiro com a globalização, a redução de gastos públicos, o aumento do desemprego e o empobrecimento da população. Tudo isso tem contribuído de forma considerável para o encaminhamento de crianças e adolescentes para a exploração sexual.

As crianças sujeitas a esse tipo de violência são oriundas de famílias privadas dos direitos básicos, mais vulneráveis a esta situação. Muitas abandonam o lar e vão para as ruas, ficando expostas aos exploradores sexuais: "[...] são as exploradas economicamente que acumulam, na 
maioria, a condição de exploradas sexualmente. São os filhos e as filhas dos excluídos e dominadas pela economia capitalista que vão buscar sustento na periferia prostituída pelo capitalismo" (FALEIROS, 2004, p. 63).

Crianças abandonadas, moradores de rua e pequenos trabalhadores são os que se envolvem com a prostituição de rua, contudo, nem toda criança pobre, miserável é explorada sexualmente. Nessa perspectiva, pontua-se que crianças e adolescentes têm o direito à proteção integral que deve ser assegurada, principalmente, pelo Estado, responsável por formular e executar políticas públicas que atendam as demandas da sociedade, incluindo a infância. Nesse sentido, o poder público tem papel fundamental no enfrentamento à violência sexual contra crianças e adolescentes.

Considerando que um dos principais determinantes da inserção de crianças e adolescente no mercado do sexo é a pobreza e a exclusão sócio-econômica (da escola, do consumo, mercado de trabalho, da saúde, da cultura), o enfrentamento desse problema passa obrigatoriamente, pela inclusão, através do acesso a políticas sociais públicas, responsabilidade exclusiva do Estado (FALEIROS, 2000, p. 34).

A garantia de políticas públicas representa o compromisso e a responsabilidade do Estado no enfrentamento da violência sexual contra crianças e adolescentes. Conforme Barbosa (1999, p. 29) a exploração sexual "[...] se fortalece da falta de compromisso do Estado, que não cumpre seu papel de garantir os direitos fundamentais da população infantojuvenil".

Em resposta a essa violência sexual configura-se a Rede de Proteção à Infância, que une diferentes políticas públicas intersetoriais implementadas por um conjunto articulado de ações governamentais e não governamentais da União, dos Estados, do Distrito Federal e dos Municípios. Nesse cenário encontra-se a Política Nacional de Assistência Social de 2004, com papel importante no Sistema de Garantia de Direitos. A assistência social organiza-se em Proteção Social Básica (de caráter preventivo) e em Proteção Social Especial (quando há violação de direitos), que exige atenção em serviços ou em centros especializados.

A proteção social especial é a modalidade de atendimento assistencial destinada a famílias e indivíduos que se encontram em situação de risco pessoal e social, por ocorrência de abandono, maus tratos físicos e, ou, psíquicos, abuso sexual, uso de substâncias psicoativas, cumprimento de medidas sócio-educativas, situação de rua, situação de trabalho infantil, entre outros (BRASIL, 2004, p. 38)

Essa proteção social especial pode ser de média e de alta complexidade. 0 primeiro nível atende famílias e indivíduos que, apesar de seus direito violados, não romperam os vínculos familiares e comunitários e têm como referência o CREAS; o segundo nível busca garantir a proteção integral - moradia, alimentação, higienização e trabalho protegido - para famílias e indivíduos que se encontram sem referência e/ou em situação de ameaça, com necessidade de serem retirados de seu 
núcleo familiar e/ou comunitário (BRASIL, 2004). A partir desta conquista, tem-se a Lei n.12.435, de 06 de julho de 2011 que, em seu artigo 6-A, inciso II, define proteção social especial como 0

[...] conjunto de serviços, programas e projetos que tem por objetivo contribuir para a reconstrução de vínculos familiares e comunitários, a defesa de direito, o fortalecimento das potencialidades e aquisições e a proteção de famílias e indivíduos para 0 enfrentamento das situações de violação de direitos (BRASIL, 2011).

A média complexidade, conforme já sinalizado, oferece serviços, programas e projetos de caráter especializado - tais como o Serviço de Proteção e Atendimento Especializado a Famílias e Indivíduos (PAEFI), ofertado pelo CREAS - a pessoas cujos direitos foram violados, mas que não perderam seus vínculos familiares e comunitários. O PAEFI é um

\begin{abstract}
Serviço de apoio, orientação e acompanhamento a famílias com um ou mais de seus membros em situação de ameaça ou violação de direitos. Compreende atenções e orientações direcionadas para a promoção de direitos, a preservação e o fortalecimento de vínculos familiares, comunitários e sociais e para o fortalecimento da função protetiva das famílias diante do conjunto de condições que as vulnerabilizam e/ou as submetem a situações de risco pessoal e social (BRASIL, 2009b, p. 18).
\end{abstract}

Os serviços especializados de caráter continuado para famílias e indivíduos em situações de risco pessoal e social por violações de direitos, consoante dispõe a Tipificação Nacional de Serviços Socioassistenciais e o PAEFI, com atendimento a crianças, adolescentes, jovens, adultos, idosos e famílias com as mais variadas formas de violência - incorporou, após a Resolução n¹09, do Conselho Nacional de Assistência Social (CNAS), o Serviço de Enfrentamento à Violência, ao Abuso e à Exploração Sexual contra criança e do adolescente. E de que maneira esses serviços estão sendo oferecidos e qual seu impacto na vida das adolescentes em situação de violência sexual e os familiares atendidos pelo CREAS em Manaus? Eis a questão que abordaremos a seguir.

\title{
3 A VISÃO DE ADOLESCENTES E FAMILIARES SOBRE 0 ATENDIMENTO ESPECIALIZADO DO CREAS
}

Neste tópico será apresentada a visão de adolescentes e familiares sobre 0 atendimento especializado do CREAS, garantido por meio do PAEFI. É importante ressaltar que o trabalho social no CREAS "pressupõe escuta qualificada e compreensão da situação vivenciada por cada família/indivíduo, considerando o seu contexto familiar, social, histórico, econômico e cultura." (PEREIRA et al., 2011, p. 58). Nesse sentido, foram escutadas as adolescentes e suas mães ${ }^{4}$ sobre 0 ACOLHIMENTO no CREAS. A seguir a resposta das adolescentes.

Bem, eles sempre tratam a gente com educação, tentando ajudar no que podem quando a gente vem aqui [no CREAS] (Luz do Sol). 
Bem, foram legais e educados com a gente, não ficaram tipo, falando que a culpa era minha, ou que eu podia ter feito alguma coisa, como os outros. Eles apoiam a gente e conversam com a gente pra gente se sentir bem, pra saber que a culpa não foi minha e que eu posso superar o que aconteceu e ter uma vida normal como todo mundo, porque ninguém sabe como é os outros ficar apontando a gente por causa daquilo como se fosse nossa culpa (Flor de Liz).

A gente foi bem acolhido lá. Eles primeiro vieram aqui em casa pra conversar com a gente, daí marcaram pra gente ir lá e daí a gente foi lá [no CREAS] pra eles poderem atender a gente direito, porque lá eles têm onde falar com a gente sem que ninguém ouça (Jasmim).

Bem acolhidos. Elas foram muito bacanas com a gente, conversaram, explicaram as coisas que a gente tinha que saber (Cravo).

As falas das adolescentes permitem-nos inferir que a acolhida inicial tem favorecido a aproximação dos usuários com a equipe técnica. Essa postura acolhedora, não discriminadora, é fundamental para conquistar a confiança das adolescentes em situação de violência sexual. Percebese, na fala de Jasmim - "sem que ninguém ouça" - o destaque quanto à privacidade da criança e do adolescente vítima ou testemunha de violência. Procura-se, assim, garantir segurança na acolhida em condições de respeito e dignidade. Quanto às mães das adolescentes, o que elas pensam a respeito do atendimento pode ser verificado nas respostas a seguir.

Fomos bem atendidas desde a recepção, todos trataram e tratam a gente super bem, os profissionais com toda presteza falaram com a gente dando apoio e orientando a gente sobre o que a gente devia fazer em relação ao que aconteceu (Beija-flor).

Fomos bem acolhidas, todos lá nos tratam super bem e na medida daquilo que podem fazer, eles tentam nos ajudar, porque é complicado passar por isso e a gente precisa de apoio. Ser tratada bem é importante pra gente, porque depois de tudo que a gente passa, tudo que a gente não quer é que as filhas da gente sejam maltratadas pelas pessoas por aí.[...] elas foram super bacanas com a gente, conversaram, ouviram a gente e trataram a gente muito bem, e daí esse medo de ter os outros apontando o dedo pra gente eu não tenho aqui, porque aqui elas sabem o que a gente passou, elas entendem nossa situação e tentam ajudar sempre (Sabiá).

0 acolhimento foi muito bom. Elas primeiro vieram na casa da gente e explicaram como 0 CREAS funcionava e como eram os atendimentos, depois elas já marcaram pra gente ir lá começar o acompanhamento. Isso foi muito bom. Elas foram a todo momento muito educadas e trataram a gente com zelo (Bem-te-vi).

Muito bem recebidas por todos e isso foi muito bom, pois quebra um pouco da nossa resistência em ir até esses locais, porque nosso medo depois do que a gente passa é ser mal atendida nos lugares onde a gente procura atendimento por causa do que a gente passou, como a gente fica vendo por aí, não quero isso pra minha filha (Andorinha).

A fala das mães acompanha a fala das adolescentes quanto ao modo de ver 0 acolhimento, qualificando-o, como se pode perceber pelo uso das expressões "bem atendidas", "bem acolhidas", "muito bom", "muito bem recebida por todos". Além disso, barreiras do preconceito, do estigma já foram quebradas na acolhida/no atendimento inicial, é o que se evidencia nas falas "quebra um pouco da nossa resistência", "esse medo de ter outros apontando o dedo pra gente, eu não tenho 
aqui". Reiteramos que essa avaliação positiva das mães é muito importante. Dez vezes foram mencionados os termos bem e bom referindo-se ao acolhimento, e, ainda, sete vezes os termos super e muito para qualificar esse bom acolhimento, ou seja, muito/super bom. Houve, assim, uma boa receptividade, garantindo um atendimento digno, respeitoso e atencioso dos profissionais, que é um dos direitos socioassistenciais previstos nos serviços ofertados no CREAS.

Achado fundamental da pesquisa refere-se ao ATENDIMENTO/ACOMPANHAMENTO especializado de adolescentes e familiares recebidos no CREAS, conforme se percebe na fala das próprias adolescentes, a seguir transcritas.

\begin{abstract}
A Assistente Social fala sobre os nossos direitos, sobre como a gente pode tentar junto da nossa família superar o que aconteceu. A Psicóloga pergunta umas coisas, mas não julga a gente, ela só escuta e depois conversa com a gente pra gente se sentir bem. A Advogada, ela explica pra mamãe onde a gente pode ir para conseguir nossos direitos e como ela pode fazer pra proteger eu e minha irmã dessas coisas e daí minha mãe vai lá [...] 0 apoio delas é sempre no sentido de fazer a gente acreditar que pode superar isso junto da nossa família (Luz do Sol).
\end{abstract}

A Assistente Social e a Advogada falam com minha mãe sobre o que ela precisa fazer para ter nossos direitos [...] A Assistente Social, ela fala que a gente precisa ficar junto para superar isso. Daí quando chega minha vez na Psicóloga, ela conversa comigo pra eu me sentir melhor, fala sobre o que aconteceu, isso é legal porque faz amenizar mais as coisas ruins que eu sinto por causa do que aconteceu, mas ela diz que não pode mudar o que aconteceu mas pode me ajudar a enfrentar isso me dando força para seguir em frente. Elas apoiam a gente fazendo a gente ver que com a nossa família junto com a gente é possível esquecer isso e viver nossa vida, e isso faz a gente acreditar na gente e ter esperança de que pode mudar nossa vida (Flor de Liz).

A Assistente Social primeiro falou com minha avó que foi lá pra ver como ia ser, daí quando eu e minha mãe fomos, ela conversou com a gente, falou sobre o lugar, explicou como eram as coisas e como a gente ia fazer para ser atendida quando ela marcasse. Daí, ela e a Psicóloga falam sobre os direitos que a gente tem e aonde minha mãe tem que ir pra conseguir proteger a gente daquilo de como a gente precisa ta junto pra se proteger $\mathrm{e}$ superar as coisas. Elas apoiam muito a gente, colocando a gente pra cima, fazendo acreditar que a gente pode vencer isso tudo, e isso me faz me sentir melhor (Jasmim)

Elas dão esclarecimento sobre as coisas que a gente não sabia antes, sobre meus direitos, onde minha mãe tem que ir buscar atendimento se eu precisar e onde a gente pode ir tentar conseguir mudar de vida e se proteger daquelas coisas que elas falam (Cravo).

As adolescentes pontuaram a questão dos direitos como sendo uma das orientações recebidas pela equipe técnica (todas enfatizaram esse aspecto). 0 direito dessas meninas a uma sexualidade saudável foi violado, mas o acompanhamento especializado contribui para a restauração do direito à proteção - ainda que não modifique a violência ocorrida - e pode ajudar a amenizar as marcas e os impactos causados pela violência sexual.

As falas registradas apontam para esse sentido: "ela conversa comigo para eu me sentir melhor [...] isso é legal porque faz amenizar mais as coisas ruins que eu sinto"; "não julga a gente, ela só escuta e depois conversa com a gente pra gente se sentir bem"; "elas apoiam muito a gente [...] fazendo a gente acreditar que a gente pode vencer tudo isso, e isso me faz sentir melhor". Tais 
manifestações das adolescentes apontam o impacto do serviço especializado na sua vida e de seus familiares. Como previsto pelo PAEFI, o serviço é de apoio, orientação e acompanhamento a famílias em situação de violação de direitos.

Aspecto igualmente interessante na fala de todas as adolescentes é a questão da superação. $O$ atendimento visa a que a adolescente, juntamente com sua família, de alguma forma, supere a situação de violência sofrida, estando esse objetivo bem presente em suas falas: "tentar junto da nossa família superar o que aconteceu"; "ficar junto para superar isso"; "vencer tudo isso"; " tentar mudar de vida". Noutras palavras, o trabalho técnico está sendo direcionado para o fortalecimento da família quanto à função protetiva. Quanto à visão das mães sobre 0 atendimento recebido no CREAS, foram registradas as falas a seguir.

A gente chega aqui, primeiro a gente falou com a assistente social que perguntou umas coisas para fazer nossa ficha, daí ela marcou o dia pra gente vir falar com a psicóloga que recebeu a gente com muita educação e ouviu a gente sobre o que tinha acontecido, e isso é bacana porque a gente não aceita que esse tipo de coisa tenha acontecido, mas aí ela conversa com a gente sobre isso explicando tudo. Daí a gente conversa com a advogada que fala sobre nossos direitos e o que a gente tem que fazer para conseguir se proteger $e$ proteger ela (filha) das coisas que aconteceu (Beija-flor).

A gente é atendida pela assistente social, pela psicóloga e a advogada. Os atendimentos são agendados por elas (profissionais) e elas ligam pra gente pra avisar o dia e o horário que a gente tem que vir e quem vai atender a gente aqui. É importante a gente saber quem atende nossos filhos nessa situação, porque qualquer coisa a gente sabe quem procurar e isso facilita e até mostra que a gente realmente se importa com o que elas passaram (Sabiá).

Assistente social e psicóloga só. Elas nos atendem e conversam com a gente explicando nossos direitos e 0 que a gente precisa fazer pra conseguir as coisas que a gente pode precisar, porque as vezes a gente não sabe das coisas, daí elas falam tudo e depois elas marcam o dia que a gente tem que ir lá (CREAS) para falar com a psicóloga sobre o que aconteceu (Bem-te-vi).

Só a psicóloga que conversa com ela (filha), explica as coisas, aconselha ela pra que possa superar né o que aconteceu, que é difícil. Mas elas fazem tudo certinho, elas marcam o dia e o horário pra gente ir lá, depois confirmam pra gente e o quando precisa elas conversam comigo, me explicam como posso ajudar ela (filha) a superar o que aconteceu. Mas só ela é atendida eu só acompanho (Andorinha).

O atendimento psicossocial e jurídico é necessário para garantir 0 atendimento qualificado. Todos os CREAS devem ter em sua equipe de referência assistente sociais, advogados e psicólogos. No entanto, um dos CREAS não contava, no momento da pesquisa, com um advogado em seu quadro. Duas mães declararam que são atendidas pelos três profissionais - assistente social, psicólogo e advogado -; outra, somente pelo assistente social e psicólogo; a quarta, apenas acompanha a filha, mas não é atendida pela equipe técnica.

O atendimento às mães responsáveis pelo acompanhamento das filhas ao CREAS está, geralmente, direcionado para a explicação dos direitos da adolescente e da família, das formas de 
proteção e do acesso as informações. Noutras palavras, o trabalho social está sendo feito de forma que os usuários do serviço tenham o conhecimento dos direitos socioassistenciais e possam acessá-los.

O modo como o atendimento está sendo feito, na visão das mães, é satisfatório. Quando questionadas sobre as limitações dos profissionais em relação ao atendimento recebido, a maioria das mães não as identificam, pelo contrário, ressaltam os esforços dos profissionais em superar as limitações para garantir um bom atendimento.

Se existem limitações, elas (profissionais) não deixam a gente perceber, porque nunca vi algo que elas não pudessem fazer pela gente. Nos atendimentos que a gente precisa e elas não podem oferecer aqui (no CREAS), elas buscam em outros lugares e conseguem, depois só nos ligam para avisar onde a gente tem que ir (Beija-Flor).

Elas são muito empenhadas no trabalho delas e estão sempre disponíveis para nós e tentam ajudar em tudo que podem e isso é muito bom para nós. Elas são ótimas, se enfrentam algum limite, elas não deixam a gente perceber (Bem-te-vi).

Elas são muito empenhadas em ajudar e em atender a gente sabe, em procurar ver melhora para gente. Elas conseguem atendimento para gente em outros lugares, tentam resolver algumas coisas que a gente as vezes não consegue, e não vejo elas terem problemas não, eu vejo nelas o que falta em outros por ai, que é respeito pela gente, pelo que a gente ta passando e compromisso com a gente, não é todo lugar que tem pessoas assim não (Sabiá).

As mães entrevistadas destacam o atendimento por meio de duas expressões: a qualidade do atendimento ("muito empenhadas", "ótimas", "nunca vi algo que não pudessem fazer", "não vejo elas terem problema não", "sempre disponíveis", " respeito pela gente"); e a articulação com outros órgãos ("buscam outros lugares e conseguem", "conseguem atendimento para gente em outros lugares").

É importante ressaltar que existem muitos limites institucionais e profissionais, mas, aos olhos dessas mães, todo o esforço dos técnicos tem garantido o atendimento de qualidade, seja no CREAS, seja por meio de encaminhamento a outros serviços e a outras instituições, tais como os Centros de Atenção Psicossocial (CAPS) e a defensoria pública. Uma das mães, porém, faz críticas ao atendimento recebido pela filha, como se pode notar em seu depoimento, a seguir transcrito.

Só acho que deveriam fazer um acompanhamento melhor, pois só conversam e falam do que aconteceu. Acho que poderiam ir além, ajudar mesmo a superar aquilo, porque é difícil ir lá e só ficar falando do que aconteceu, ela (filha) precisa conseguir esquecer, a gente faz nossa parte, estar com ela para tudo, dando apoio, mas ela também precisa da ajuda delas (profissionais) para enfrentar e superar tudo isso, e nessa parte acho que elas poderiam melhorar, porque como tem sido acho que não tem ajudado muito não (Andorinha).

A visão desta mãe (Andorinha) quanto ao atendimento aponta certa ambiguidade. Ela diz que 0 atual atendimento não tem ajudado muito, mas também afirma que "Elas fazem tudo certinho, [...] quando precisa elas conversam comigo, me explicam como posso ajudar ela (filha) a superar o que aconteceu, mas, só ela é atendida, eu só acompanho". Ela é a única mãe não "atendida" pelo PAEFI: "[...] Eu venho com ela nos dias de atendimento, as vezes converso com as profissionais para saber da 
minha filha, mas sempre só ela é atendida mesmo". A própria filha, quando questionada sobre quem da família é acompanhada pelo CREAS, responde: "Ninguém precisa, só eu que passei por aquilo ninguém mais [...] só eu converso com a psicóloga".

Pode-se inferir que o fato de não haver um atendimento psicológico conjunto para mãe e filha não significa que não haja um acompanhamento familiar - a própria mãe reconhece a necessidade de conversar com as profissionais sobre a filha e faz isso. Contudo, há um desejo de que a filha supere logo o que aconteceu, e, quanto a isso, ela declara que as profissionais poderiam melhorar.

Além do acolhimento e do acompanhamento especializado recebido pelas famílias, um terceiro ponto é considerado nesta reflexão: a questão do impacto. Qual tem sido o impacto do atendimento especializado na vida das adolescentes que sofreram violência sexual e de seus familiares?

Será visto, a respeito desse aspecto, o ponto de vista das adolescentes. Trata-se de identificar suas representações sobre os impactos do atendimento (Quadro 1), e não uma descrição do impacto em si, tendo-se, desse forma, perguntado às entrevistadas se o CREAS/PAEFI contribui para que elas e suas famílias consigam superar a violência sexual sofrida e, ainda, o que mudou depois do acompanhamento.

Quadro 1 - Representações das adolescentes sobre os impactos de seu atendimento no CREAS

\begin{tabular}{|c|c|c|}
\hline \multicolumn{3}{|c|}{ OS IMPACTOS DO ATENDIMENTO ESPECIALIZADO - visão das adolescentes } \\
\hline Nome & $\begin{array}{c}\text { As contribuições do CREAS-PAEFI na vida das } \\
\text { adolescentes e familiares para superação da } \\
\text { violação sofrida }\end{array}$ & $\begin{array}{c}\text { O que mudou na vida da adolescente e da } \\
\text { sua família após o acompanhamento no } \\
\text { CREAS }\end{array}$ \\
\hline Luz do Sol & $\begin{array}{l}\text { Contribui muito, porque se não fosse aqui, acho que } \\
\text { não teria onde ir. Minha mãe não tem como pagar pra } \\
\text { me atender, e os outros lugares que não cobram são } \\
\text { bem longe, daí ia ficar sem ser atendida, em casa. } \\
\text { Então, a gente precisa daqui pra que eu possa ter } \\
\text { meus direitos e pra gente conseguir superar aquilo que } \\
\text { fizeram com a gente, porque é difícil esquecer e } \\
\text { encarar tudo isso, e sem elas (profissionais) acho que } \\
\text { ia ficar pior, ia ser só eu, a mãe e a mana, nem sei } \\
\text { dizer como ia ser, quero pensar nisso não, melhor ter } \\
\text { elas (profissionais) para contar. }\end{array}$ & $\begin{array}{l}\text { Mudou a maneira como eu devo lidar com a } \\
\text { sociedade e com o que me aconteceu. Antes } \\
\text { eu achava que sempre ia passar por isso e } \\
\text { que ninguém ia acreditar em mim, mas agora } \\
\text { eu sei que não é assim. Não foi culpa minha } \\
\text { e hoje por causa de vir aqui falar com elas, } \\
\text { eu sei disso e vejo de outro jeito. }\end{array}$ \\
\hline Flor de Liz & $\begin{array}{l}\text { Contribui sim atendendo a gente, explicando tudo, } \\
\text { conversando com a gente, apesar de às vezes } \\
\text { atrapalhar na escola, mas é bom poder conversar } \\
\text { sobre como enfrentar as coisas, sem que fiquem me } \\
\text { julgando e que me entendem, isso alivia um pouco o } \\
\text { peso da gente, a nossa dor e ajuda a gente a tentar } \\
\text { superar aquilo que aconteceu. }\end{array}$ & $\begin{array}{l}\text { Melhorou minha relação com a minha família, } \\
\text { aproximou mais a gente, porque agora a } \\
\text { gente se ajuda e tenta superar junto o que } \\
\text { aconteceu comigo. Não me sinto mais só } \\
\text { como antes. Mas as vezes fica um pouco } \\
\text { complicado por causa do horário que as } \\
\text { vezes atrapalha na escola. }\end{array}$ \\
\hline Jasmim & $\begin{array}{l}\text { Contribui bastante para um futuro melhor pra gente, } \\
\text { ajudando a superar aquilo que aconteceu, acreditando } \\
\text { em mim e me dizendo sempre que posso ter um futuro } \\
\text { diferente e que não é porque aquilo aconteceu que não } \\
\text { posso ser uma pessoa normal, com uma vida normal }\end{array}$ & $\begin{array}{l}\text { Passei a me sentir mais acolhida por todos e } \\
\text { me aproximou mais da minha família que } \\
\text { agora ta ainda mais comigo do que antes, é } \\
\text { bem legal sentir mais confiança de que tudo } \\
\text { vai dar certo e de que eu posso encarar isso }\end{array}$ \\
\hline
\end{tabular}




\begin{tabular}{|c|c|c|}
\hline & perto de quem eu gosto. & $\begin{array}{l}\text { e superar o que aconteceu. Antes eu achava } \\
\text { que sempre iam me apontar por causa } \\
\text { daquilo, mas elas (profissionais) falam que } \\
\text { não e que eu posso ter uma vida diferente } \\
\text { agora sem passar por aquilo de novo. }\end{array}$ \\
\hline Cravo & $\begin{array}{l}\text { Contribui, porque tem gente que precisa muito desses } \\
\text { acompanhamentos por causa do que passam. E } \\
\text { apesar de pra mim não ser importante acho que pros } \\
\text { outros pode ajudar a enfrentar o que aconteceu, } \\
\text { porque eles tentam dar força pra gente superar e } \\
\text { tentar ter uma vida como os outros. }\end{array}$ & $\begin{array}{l}\text { Apesar de ser atendida, não vi nenhuma } \\
\text { mudança, continua tudo igual. A gente só } \\
\text { tem umas explicações das coisas, mas isso } \\
\text { não mudou nada na minha vida nem da } \\
\text { minha família. Por isso, não entendo por que } \\
\text { tenho que vir. Vir para cá (CREAS) não vai } \\
\text { mudar o que aconteceu comigo nem vai } \\
\text { apagar o que eu já passei por causa disso, } \\
\text { se pudesse escolher não vinha. Não vai } \\
\text { adiantar nada mesmo. }\end{array}$ \\
\hline
\end{tabular}

Fonte: Elaborado pela autora.

As adolescentes são unânimes em afirmar a contribuição do acompanhamento especializado recebido no CREAS. Elas destacam a palavra superação, presente na fala de todas: "conseguir superar", "tentar superar", "ajudando a superar" e "dar força pra gente superar". Também qualificam a intensidade da contribuição por meio das palavras "sim", "muito" e "bastante".

E o que mudou na vida das adolescentes? Flor de Liz e Jasmim apontam as mudanças em relação à família, ou seja, elas se aproximaram mais da família; Luz do Sol destaca a mudança ocorrida na forma de lidar com a sociedade e com a violência sofrida. Ou seja, há uma tentativa de abandonar as lembranças, ressignificar a memória e possibilitar, assim, um empoderamento de sua própria vida. Cravo tem seu pensamento centrado principalmente nas lembranças da violência que a afetam e ressalta que nada vai mudar o que sofreu e que preferia não ter 0 acompanhamento, pois não o considera necessário. Essa fala da adolescente Cravo aponta as dificuldades experimentadas para a superação da experiência negativa. Em outras falas suas, no entanto, ela reconhece a importância do acompanhamento recebido pela psicóloga: "Ela conversa comigo e dá uns conselhos, é bacana, ela me ouve e isso é legal, faz com que eu não me sinta só". Há também impactos negativos: "atrapalha as vezes no horário da escola", como pontuado por Flor de Liz.

Quanto às mães, elas explicitaram em seus discursos mudanças na vida das famílias e de suas filhas após o acompanhamento no CREAS.

Mudou principalmente minha relação com ela, porque agora a gente está mais próxima do que antes e elas nos atendimentos reforçam essa importância da gente se apoiar e ficar juntas para superar o que aconteceu. Não é fácil porque ela mudou muito, eu também, tudo mudou depois daquilo, o que já não era fácil, ficou pior, mas a gente tá tentando juntas, a gente conversa mais agora, sem segredos, nem medo porque tudo que quero é proteger ela e a irmã dela de todo mal (Beija-flor).

Muita coisa mudou graças ao acompanhamento que a gente recebe. Desde que ela (filha) contou sobre o que aconteceu a gente passou, passou não, tem passado por muita coisa e desde que viemos pra cá, elas tentam passar um pouco de tranquilidade e força pra gente, incentivando a gente a se apoiar, ficar juntos e isso é muito importante nesse momento. 
Eles apoiam muito a gente e sempre que a gente precisa eles ajudam no que podem. [...] hoje eu sei o que preciso fazer pra proteger minhas filhas e eu mesma, sei como fazer para ter acesso a outros serviços e quais são meus direitos (Sabiá).

Ficou muito mais fácil lidar com a situação, pois com isso a gente aprende como se proteger e proteger elas disso. Fora que depois que nós fomos pra lá (no CREAS) para ser acompanhadas, ela deixou mais de se isolar, ficou menos estranha sabe e hoje conversa mais comigo sobre tudo, porque com o apoio que a gente teve lá (no CREAS), a gente tem aprendido a confiar mais uma na outra e que ela pode contar com a gente pra tudo. Elas (profissionais) sempre falam disso né da gente (Família) ficar junto para enfrentar isso, isso (abuso), mesmo que de um jeito ruim aproximou mais a gente (Bem-te-vi).

Ajudou a fazer com que eu entendesse mais ela (filha) e sobre como lidar com essa situação. Era muito difícil antes e agora as coisas parecem estar amenizando, principalmente entre a gente, pois a gente brigava muito. Daí, passamos a conversar mais e tentar confiar mais uma na outra. Tento fazer o meu máximo para tentar estar com ela e entender o que ela tem passado, mas é difícil, porque as vezes ela fica fechada e não quer falar com ninguém, mas a gente tem que ter paciência, porque apesar de saber o que aconteceu, a gente não sabe como ela se sente de verdade. $E$ acho que mudou também como ela mesmo se vê nessa situação, antes elas chorava muito e ficava isolada, hoje eu vejo ela mais forte pra enfrentar isso, e tenho certeza que é graças a elas (profissionais) que tem ajudado ela a se encontrar no meio dessa confusão que deve tá na cabeça dela, porque ela hoje sorri muito mais do antes de tudo isso (Andorinha).

Todas as mães são unânimes em destacar o CREAS/PAEFI com um apoio importante relacionado à proteção, o qual tem gerado mudança na vida de suas famílias, principalmente no diálogo com as filhas. A palavra conversa aparece em todas as falas: "a gente conversa mais agora"; "conversa mais"; "passamos a conversar mais". Há também a conversa com as profissionais que orientam quanto à proteção, à superação e ao acesso a serviços da rede local.

É nítido o efeito do atendimento na relação com as filhas: "muita coisa mudou graças ao acompanhamento"; "ficou mais fácil lidar com a situação"; "ajudou a fazer com que eu entendesse mais ela"; "mudou principalmente minha relação com ela"; "mudou como ela se vê na situação". Pode-se afirmar, dessa forma, que mudanças ocorreram na vida das adolescentes e de suas mães.

\section{CONCLUSÃO}

$\mathrm{Na}$ visão das adolescentes e das mães o acompanhamento especializado do CREAS/PAEFI tem impactado positivamente suas vidas como usuárias deste serviço.

$\mathrm{O}$ acolhimento e a receptividade inicial têm garantido um atendimento com dignidade e respeito; o atendimento sistematizado e especializado ao longo dos acompanhamentos tem proporcionado escuta, orientações quantos aos direitos das usuárias e encaminhamento a serviços da rede local de proteção quando necessário.

Além disso, o acompanhamento tem impactado a vida das adolescentes - os vínculos familiares têm sido fortalecidos e a maioria das adolescentes reconhecem sinais de mudanças em seus 
comportamentos, em sua forma de lidar com a situação vivenciada. Trata-se, porém, de um processo, e não de uma mudança instantânea.

As mães foram 'empoderadas', pois ampliaram informações sobre seus direitos e sobre meios para proteger suas filhas, estando hoje mais próximas delas, o que se evidencia pelo fortalecimento do diálogo familiar. Destacam também que se sentiram respeitadas, valorizadas, e não foram culpabilizadas pela situação de violência sexual ocorrida com suas filhas.

Pode-se afirmar, assim, que o desafio é dar continuidade ao acompanhamento especializado com vistas à consolidação da rede de apoio ao seu público.

\section{REFERÊNCIAS}

AZAMBUJA, Maria Regina Fay de. Inquirição da Criança Vítima da Violência Sexual: proteção ou violação de direitos? Porto Alegre. Livraria Advogado, 2011.

BARBOSA, Hélia. Abuso e exploração sexual de crianças. Causas, prevenção e atendimento no Brasil. In: ABRANET. Inocência em perigo: abuso sexual de crianças, pornografia infantil e pedofilia na internet. Rio de Janeiro: Garmond, 1999.

BRASIL. Política Nacional de Assistência Social (PNAS). Brasília: Ministério do Desenvolvimento Social e Combate à Fome, 2004.

BRASIL. Lei $\mathrm{n}^{0}$ 12.015, de 7 de agosto de 2009. Altera o Título VI da Parte Especial do Decreto-Lei no 2.848, de 7 de dezembro de 1940 - Código Penal. 2009a.

BRASIL. Resolução 109, de 11 de novembro de 2009. Aprova a Tipificação Nacional de Serviços Socioassistenciais. Diário Oficial da União, Brasília, DF, n. 225, nov. 2009. Seção I. 2009b.

BRASIL. Lei $n^{0}$ 12.435, de 6 de Julho de 2011. Altera a Lei $n^{0}$ 8.742, de 7 de dezembro de 1993, que dispõe sobre a organização da Assistência Socia. Disponível em http://www.planalto.gov.br/ccivil_03/_Ato2011-2014/2011/Lei/L12435.htm. Acesso em: abril 2020.

BRASIL. Plano Nacional de Enfrentamento da Violência Sexual contra Criança e Adolescente. Maio 2013. Disponível em:

http://www.crianca.mppr.mp.br/arquivos/File/publi/sedh/08_2013_pnevsca.pdf. Acesso em: abril 2020.

BRASIL. Ministério da Mulher, da Família e Direitos Humanos. Disque Denúncia Nacional de Abuso e Exploração Sexual contra Criança e Adolescente - Disque 100. Balanço 2011-2019/1 - Módulo Criança e Adolescente. 2019. Disponível em: https://www.mdh.gov.br/informacao-aocidadao/ouvidoria/balanco-disque-100. Acesso em: 28 jan. 2020.

CERQUEIRA, Daniel; COELHO, Danilo Santa Cruz. Nota Técnica. Estupro no Brasil: uma radiografia segundo os dados da Saúde (versão preliminar). Brasília: IPEA, 2014.

CERQUEIRA, Daniel et al. Atlas da Violência 2018. Rio de Janeiro: Instituto de Pesquisa Econômica Aplicada (IPEA); Fórum Brasileiro de Segurança Pública FBSP), jun. 2018. 
DOS SANTOS, Benedito Rodrigues; IPPOLITO, Rita; NEUMANN, Marcelo. Guia Escolar: Métodos para Identificação de Sinais de Abuso e Exploração Sexual de Crianças e Adolescentes. Brasília: Secretaria Especial dos Direitos Humanos e Ministério de Educação, 2004.

FALEIROS, Eva T. Silveira. Repensando os conceitos de violência, abuso e exploração sexual de crianças e adolescentes. Brasilia: Thesaurus, 2000.

FALEIROS, Eva T. Silveira. A exploração sexual comercial de crianças e adolescentes no mercado do sexo. In: LIBÓRIO, Renata; SOUZA, Sônia (org.). A exploração sexual de crianças e adolescentes no Brasil: reflexões teóricas, relatos de pesquisa e intervencõos psicossociais. São Paulo: Casa do Psicólogo, 2004; Goiânia: Universidade Católica de Goiás, 2004.

FERNANDEZ, Cristiane; RIBEIRO, Vanessa. Vítimas do Silêncio. Revista Humanidades, Brasília [s.n.], p. 47-60, 2005.

FERRAZA, Cristina Barcaro; VERONESE, Josiane Rose Petry. Violência e exploração sexual infantojuvenil na legislação brasileira. In: VERONSE, Josiane Rose Petry (org.). Violência e exploração sexual infanto-juventil: crimes contra a humanidade. Florianópolis: OAB/SC Editora, 2005

LEITÃO, Consuelena Lopes. Limites e Possibilidades: uma tentativa de aproximação antropológica com a realidade de adolescentes em situação de exploração sexual na Cidade de Manaus. 2016. Tese. (Doutorado em Antropologia). Instituto de Filosofia Ciências Humanas e Sociais Aplicadas, Universidade Federal do Amazonas, Manaus, 2016.

NOGUEIRA NETO, Wanderlino. Sexualidade Humana. Marcos normativos referenciais para o reconhecimento e garantia dos direitos sexuais e para o enfrentamento especificamente da exploração sexual de crianças e adolescentes no Brasil. 2015. Disponível em: http://www.conselhodacrianca.al.gov.br/sala-de-imprensa/noticias/2015/outubro-1/sexualidade-humana1. Acesso em: abril 2020.

PEREIRA, Juliana Maria Fernandes et al. Orientações técnicas: Centro de Referência Especializado de Assistência Social: CREAS. Brasilia, Brasil, 2011.

PODESTÁ, Marta del Carmen; ROVEA, Ofelia Laura. Abuso Sexual Intrafamiliar: un abordaje desde el trabajo social. Buenos Airtes: Espaço Editorial, 2005.

ROURE, Glacy. Vidas silenciadas: a violência com crianças e adolescentes. São Paulo: Unicamp, 1996.

SECRETARIA DE SEGURANÇA PÚBLICA DO AMAZONAS (SSP-AM). Denúncias ajudam a reprimir violência contra crianças e adolescentes, diz delegada da DEPCA. Manaus, 29 de janeiro de 2019. Disponível em: http://www.ssp.am.gov.br/denuncias-ajudam-a-reprimir-violencia-contra-criancas-eadolescentes-diz-delegada-da-depcal. Acesso em: abril 2020.

SIQUEIRA, Priscila; QUINTEIRO, Maria (org.). Tráfico de pessoas: quanto vale o ser humano na balança comercial do lucro? a escravidão no século XXI. São Paulo: Ideias \& Letras, 2013.

SOUZA e SILVA, Maria Amélia de. Violência contra criança - quebrando o pacto do silêncio. In: FERRARI, Dalka; VECINA, Tereza. 0 fim do silêncio na violência familiar: teoria e prática. São Paulo: Ágora, 2002. 
UNICEF. Hidden in plain sight. A statistical analysis of violence against children. USA. Unicef, 2014.

VASCONCELOS, Maria Gorete; GARCIA, Claudia Fígaro. Violência sexual infanto-juvenil: da teoria à prática do Centro de Referência e Atenção à Infância e Adolescência. In: LIBÓRIO, Renata; SOUZA, Sônia (org.). A exploração sexual de crianças e adolescentes no Brasil: reflexões teóricas, relatos de pesquisa e intervenções psicossociais. São Paulo: Casa do Psicólogo, 2004; Goiânia: Universidade Católica de Goiás, 2004

VERONESE, Josiane Rose Petry. Violência e Exploração Sexual InfantoJuvenil: crimes contra a humanidade. Florianopólis, OAB/SC, 2005.

\section{Notas}

1 Ousadia, audácia. Expressão regional muito comum nas regiões Norte e Nordeste do país.

2 "submeter, induzir ou atrair à prostituição ou outra forma de exploração sexual alguém menor de 18 (dezoito) anos ou que, por enfermidade ou deficiência mental, não temo necessário discernimento para a prática do ato, facilitá-la, impedir ou dificultar que a abandone" (CP, art. 218-B, caput).

3 (Lei 8.072/90, art. 10, VIII), com a redação da Lei 12.978/2014.

${ }^{4}$ Os nomes das adolescentes e das suas mães, em vista da preservação de sua identidade, foram substituídos por pseudônimos. 